Similar results were obtained in puppies. Full details of the present work will be given elsewhere ${ }^{11}$.

\section{J. S̆TERZL}

Z. TrnKa

Division of Immunology, Institute of Biology,

Czechoslovak Academy of Science, Praha 6.

${ }^{1}$ Billingham, R. E., Brent, L., and Medawar, P. B., Nature, 172, 603 (1953)

${ }^{2}$ Haรek, Csl. biol., 2, 29, 267 (1953) ; Nature, 175, 763 (1955).

${ }^{3}$ Dixon, F. Y., and Maurer, P. H., J. Exp. Med., 101, 245 (1955)

${ }^{4}$ Buxton, A., J. Gen. Microbiol., 10, 398 (1954).

${ }^{5}$ Kerr, W. R., and Robertson, M., J. Hyg., 52, 253 (1954).

${ }^{8}$ Cohn, M., Transpl. Bull., 3, 70 (1956).

'Smith, R. T., and Bridges, R. A., Transpl. Bull., 3, 145 (1956).

8 White, C., Biometrics, 8, 33 (1952).

- Hanan, R., and Oyama, J., J. Immunol., 73, 49 (1954).

${ }^{10}$ Cinader, B., and Dubert, J. M., Brit. J. Exp. Path., 36, 515 (1955),

11 Sterzl, J., and Trnka, Z., Csl. Mikrobiol, (in the press)

\section{Polysaccharide containing Amino-Sugar from Bacillus subtilis}

SEVERAL polysaccharides containing amino-sugars have been isolated from strains of Bacillus anthracis which contain polyglutamic acid in their capsular material ${ }^{1}$. However, no polysaccharides of a similar type have as yet been reported from the related $B$. subtilis strains which produce polyglutamic acid extracellularly.

The present communication deals with the isolation and some properties of an amino-sugar containing polysaccharide obtained from such a strain of $B$. subtilis.

Cells of $B$. subtilis ATCC 9945 grown for three to four days at $36^{\circ} \mathrm{C}$. in Sauton's medium were extracted in the cold with 10 per cent trichloracetic acid solution. The trichloracetic acid was removed with ether and the polysaccharide precipitated with 3 volumes of alcohol, deproteinized by the Sevag procedure and further purified by treatment with a mixture of Lloyd's reagent and kaolin in acetic acid. The polysaccharide solution was dialysed, reprecipitated with alcohol in the presence of acetic acid and sodium acetate, washed with alcohol and ether and finally dried in vacuum. The yield was about 4 per cent of the dry weight of the cells.

The material dissolved in water after swelling, giving a highly viscous solution, of a $p \mathrm{H}$ close to 7 . An ultracentrifuge analysis indicated the presence of a single component, with a molecular weight of $100,000-200,000$. It gave a negative biuret reaction, and no significant absorption in the ultra-violet range. The indole and tryptophan reactions for polysaccharides ${ }^{2}$ were positive, and the carbazole reaction for hexuronic acids as well as the Dische primary cysteine reaction for methyl pentoses ${ }^{2}$ proved to be negative. No colour reaction was observed with iodine. An elementary analysis revealed the presence of 0.9-1 1 per cent phosphorus, $3 \cdot 8$ per cent nitrogen and no sulphur. About 20 per cent of the nitrogen was in the form of bound amino-acids, as shown by paper chromatography of acid hydrolysates, as well as by the fact that part of the $\mathrm{NH}_{2}$ (Van Slyke) groups relessed upon hydrolysis were $\alpha$-amino groups (ninhydrin-carbon dioxide). The material, after hydrolysis in $1 \mathrm{~N}$ sulphuric acid at $100^{\circ} \mathrm{C}$. for $4 \mathrm{hr}$., gave values of 60 per cent reducing sugar (Somogy ${ }^{3}$ ), calculated as glucose. The acetyl content, calculated from the volatile acid found in $p$-toluensulphonic acid hydrolysates, was $19 \cdot 5$ per cent.

For a study of the carbohydrate components, the sulphuric acid hydrolysates were neutralized with barium carbonate and chromatographed on paper in $n$-butanol/acetic acid/water $(25: 6: 25)$. Spraying with alkaline silver nitrate ${ }^{4}$ revealed the presence of two spots of equal intensity, one of which moved the same distance as galactose, gave a positive reaction with aniline phthalate, and was identified as galactose by chromatography in ethyl acetate/ pyridine/water $(2: 1: 2)$, phenol/water $(3: 1)$ and butanol/ pyridine/water $(45: 25: 40)$. The other spot, which gave no reaction with aniline phthalate but positive ninhydrin and Elson-Morgan ${ }^{5}$ reactions, when rechromatographed according to the method of Stoffyn and Jeanloz ${ }^{6}$ behaved as an equimolar mixture of galactosamine and glucosamine. Chromatograms of the hydrolysates gave a negative reaction with the naphthoresorcinol spray for ketoses ${ }^{5}$.

Thus, the polysaccharide appears to be composed mainly of galactose, $\mathrm{N}$-acetyl glucosamine and $\mathrm{N}$-acetyl galactosamine, apparently in a molar ratio of $2: 1: 1$.

Department of Biophysics,

Nathan Sharon

Weizmann Institute of Science,

Rehovoth, Israel.

Jan. 25.

${ }^{1}$ Ivanovics, G., Z. Immunitats, 97, 402 (1940). Cave-Brown-Cave, J. E., et al., J. Chem. Soc., 3866 (1954). Strange, R. E., and Belton, F. C., Brit. J. Exp. Path., 35, 153 (1954),

2 Dische, Z. "Methods Biochem. Anal.", 2, 313 (1955).

${ }^{3}$ Somogy, M., J. Biol. Chem., 160, 61 (1945).

- Trevelyan, W. E., Procter, D. P., and Harrison, J. S., Nature, 166, 444 (1850).

- Partridge, S. M., and Westall, R. G., Biochem. J., 42, 238 (1948).

'Stoffyn, P. J., and Jeanloz, R. W., Arch. Biochem. Biophys., 52, 373 (1954).

\section{Squalene Content of Various Shark Livers}

Since the demonstration that squalene might be an important precursor to cholesterol in endogenous synthesis ${ }^{1-3}$, it was felt that it would be useful to have available an adequate supply of carbon-14labelled squalene. It has been shown that synthetic squalene does not act as a precursor for cholesterol, whereas the biological squalene does ${ }^{2,4}$. The difference is apparently due to the high degree of stereospecificity. It was decided, therefore, to attempt to obtain carbon-14-labelled squalene by biological synthesis. 'The only known adequate biological producer of squalene in the northern hemisphere is the basking shark, and since the adults are large, some being well over $30 \mathrm{ft}$. long, the difficulty of injecting earbon-14-labelled acetate in such an animal and maintaining the animal alive for three days for adequate synthesis of squalene is obvious.

It was decided, therefore, to search for other sharks of a more suitable size which might also have a significantly high content of squalene in the liver. The search was conducted primarily on the west and east coasts of Florida, the Caribbean and the Gulf of Mexico. As soon as a shark was caught, it was killed and $15 \mathrm{gm}$. of the liver was ground in a mortar with $30 \mathrm{gm}$. of sodium sulphate. The mixture was then extracted with chloroform and subjected to infra-red analysis for its squalene content. In many cases, both máles and females of different ages were tested. In addition, different lobes of the liver and 